\title{
Pierre Auger (1899-1993)
}

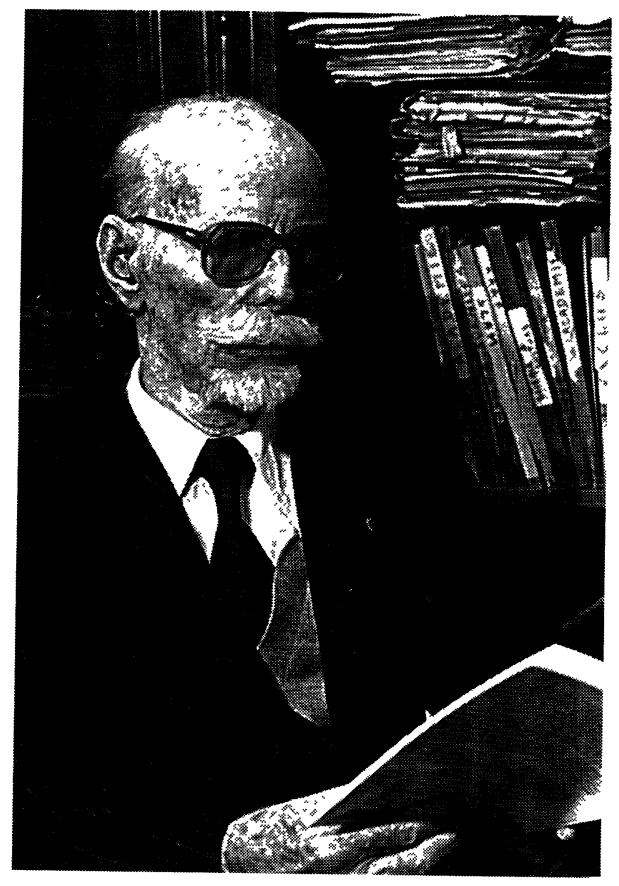

Photo Studio BOG

EN ANGLAIS DANS LE TEXTE

Quiet morning at the mountain Kind the sun and soft the air Drops of music from the fontain Roll like pearls along your hair.

Quiet noon under the trees Dark the shadow clearings bright Only life here are the bees Threads of gold across the light.

Quiet evening at the beach Cold the breeze and warm the sand Through your magic I can reach Stars at a wisp of the hand.

Pierre Auger "De çà, de là-Poèmes du temps présent" par courtoisie de Pensée Universelle, Editeur 

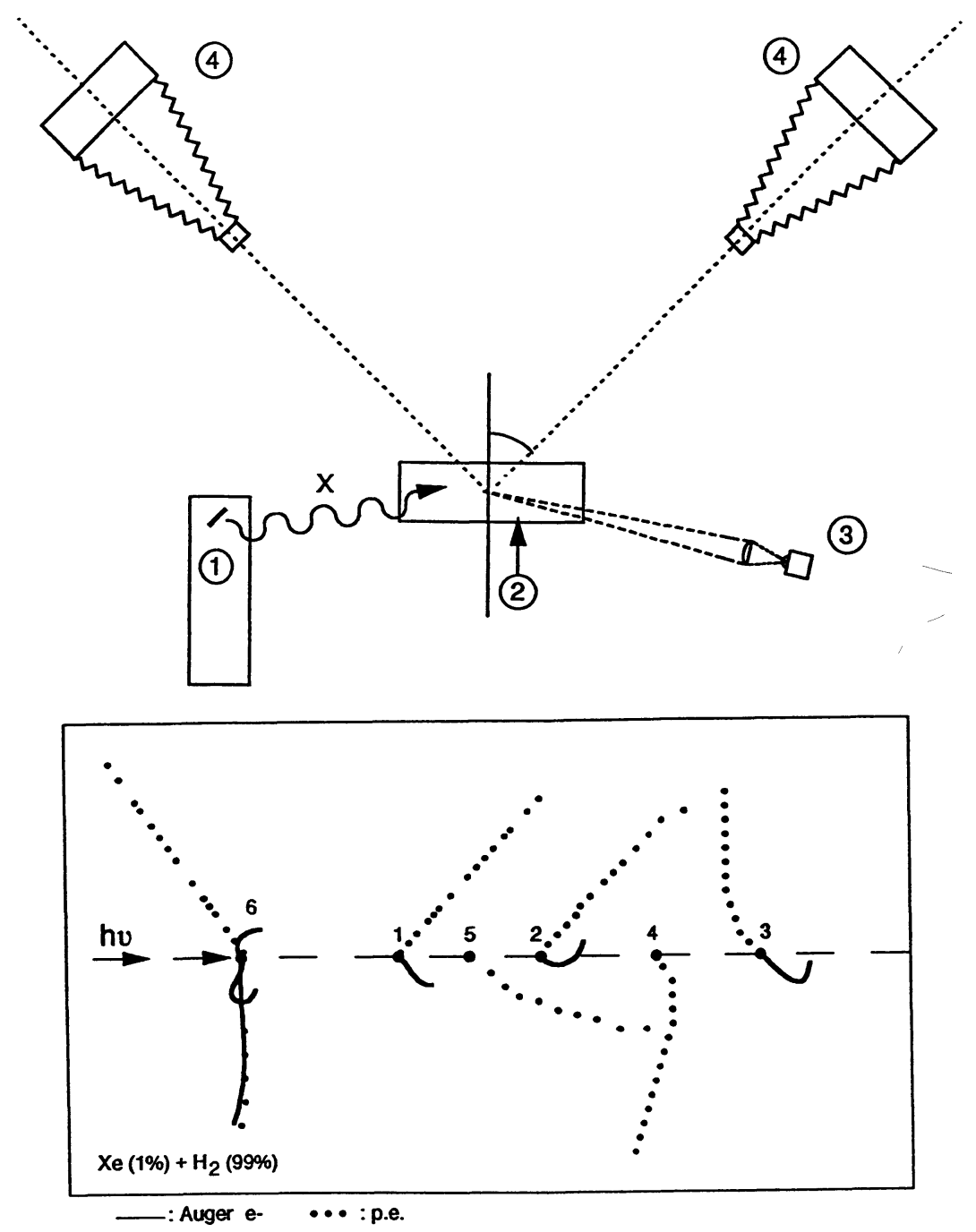

Top Schematic experimental arrangement used by Pierre Auger. $1 \mathrm{X}$-Ray tube; 2 Wilson chamber; 3 Light illumination of the chamber; 4 Photographic camera.

Bottom: Facsimile of one of the photographs then obtained: Irradiation (from the left) of a $1 \% \mathrm{Xe}-$ $99 \% \mathrm{H}_{2}$ gas by $\mathrm{MoK}_{\alpha}$ radiation (Wilson chamber). The dotted tracks represent photoelectrons trajectories and the full tracks Auger electron trajectories.

Individual $\mathrm{Xe}$ atoms are clearly localized and may be identified by the length (or energy) of the tracks.

Some Xe atoms only show the photoelectric effect (atoms $n^{\circ} 4.5$ ) while others show simultaneously photoelectron and Auger electron emissions $\left(n^{\circ} 1,2,3\right)$. Thus it is possible to evaluate the fluorescence $\omega_{i j}$ and Auger $a_{i j k}$ yields. Atom $n^{\circ} 6$ shows 3 Auger emissions (cascade process) following the photoemission effect. P. Auger also observed that the change of the photon energy does not change the length (energy) of the Auger tracks while a change in the rare gas does change them. (From P. Auger, Ann. de Phys. 10 Serie t VI (1926) 183). 